\title{
Bioplaguicidas: Mecanismos de acción biocida en insectos plaga
}

\author{
Biopesticides: Mechanisms of biocidal action in pest insects \\ Biopesticidas: Mecanismos de ação biocida em insetos-praga
}

Recibido: 07/06/2021 | Revisado: 11/06/2021 | Acepto: 13/06/2021 | Publicado: 27/06/2021

\author{
Angela Verónica Choque Miranda \\ ORCID: https://orcid.org/0000-0003-1637-8246 \\ Universidad Nacional Jorge Basadre Grohmann, Perú \\ E-mail: achoquem@unjbg.edu.pe \\ Yemile del Carmen Berrios Espejo \\ ORCID: https://orcid.org/0000-0002-9706-9949 \\ Universidad Nacional Jorge Basadre Grohmann, Perú \\ E-mail: yberriose@unjbg.edu.pe \\ Jorge Luis Tomas Florez Salas \\ ORCID: https://orcid.org/0000-0003-3533-2956 \\ Universidad Nacional de Moquegua, Perú \\ E-mail: jflorezs@ hotmail.com \\ Hebert Hernan Soto Gonzales \\ ORCID: https://orcid.org/0000-0002-9936-1943 \\ Universidad Nacional de Moquegua, Perú \\ E-mail: hsotog@unam.edu.pe \\ Jorge González Aguilera \\ ORCID: https://orcid.org/0000-0002-7308-0967 \\ Universidade Federal do Mato Grosso do Sul, Brasil \\ E-mail: j51173@yahoo.com \\ Leandris Argentel Martínez \\ ORCID: https://orcid.org/0000-0002-0353-2251 \\ Instituto Tecnológico del Valle del Yaqui, México \\ E-mail:oleinismora@gmail.com
}

\begin{abstract}
Resumen
Las plagas de insectos son la principal preocupación de los agricultores, ello los ha llevado a ejercer prácticas inadecuadas de control; provocando un uso indiscriminado de los plaguicidas químicos; lo que ha traído como consecuencia el deterioro y desarmonización del ambiente y la salud humana. En los últimos años, se tiene como una alternativa saludable para el control de los insectos plaga, a los bioplaguicidas; cuyos mecanismos de acción biocida, motivó la presente revisión. En este artículo de revisión se utilizó 63 artículos científicos de investigación en entomopatógenos, de los cuales 20 corresponden a temas desde un enfoque genético (genes de virulencia), 23 artículos detallan los mecanismos de acción por hongos entomopatógenos, 08 explican los mecanismos de acción que ejerce la bacteria Bacillus thuringiensis y 12 artículos sobre características de los bioinsecticidas microbianos comerciales. Con lo cual podemos concluir que los hongos y bacterias son los microorganismos entomopatógenos más empleados en la formulación de los bioplaguicidas, siendo las especies Metarhizium anisopliae, Beauveria bassiana y Bacillus thuringiensis las especies más utilizadas. De este último su efectividad biocida se fundamenta en la acción de la proteína Cry y de los primeros su efectividad depende de la adhesión de la espora a la cutícula del insecto plaga.
\end{abstract}

Palabras claves: Control biológico; Entomopatógeno; Adhesina; Toxina cry.

\begin{abstract}
Insect pests are the main concern of farmers, this has led them to use inadequate control practices; causing an indiscriminated use of chemical pesticides which has resulted in the deterioration and disharmonization of the environment and human health. In recent years, biopesticides have been used as a healthy alternative for the control of pest insects whose biocidal action mechanisms motivated this review. In this article, 63 scientific research articles on entomopathogens were used from which 20 correspond to topics from a genetic approach (virulence genes), 23 articles detail the mechanisms of action by entomopathogenic fungi, 08 explain the mechanisms of action that exerts the bacterium Bacillus thuringiensis and 12 articles on characteristics of commercial microbial bioinsecticides. It can be concluded that fungi and bacteria are the most entomopathogenic microorganisms used in the formulation of biopesticides, being the species Metarhizium anisopliae, Beauveria bassiana and Bacillus thuringiensis the most used species. From this last, its biocidal effectiveness is based on the action of the Cry protein and of the first mentioned its effectiveness depends on the adhesion of the spore to the cuticle of the pest insect.
\end{abstract}

Keywords: Biological control; Entomopathogenic; Adhesin; Cry toxin. 


\begin{abstract}
Resumo
As pragas de insetos são a principal preocupação dos agricultores, o que os leva a exercer práticas de controle inadequadas; causando um uso indiscriminado de pesticidas químicos; o que resultou na deterioração e desarmonização do meio ambiente e da saúde humana. Nos últimos anos, os biopesticidas têm sido utilizados como alternativa saudável para o controle de insetos-praga; cujos mecanismos de ação biocida motivaram a presente revisão. Neste artigo de revisão, foram utilizados 63 artigos de pesquisa científica sobre entomopatógenos, dos quais 20 correspondem a tópicos de uma abordagem genética (genes de virulência), 23 artigos detalham os mecanismos de ação dos fungos entomopatogênicos, 08 explicam os mecanismos de ação que exerce a bactéria Bacillus thuringiensis e 12 artigos sobre características de bioinseticidas microbianos comerciais. Com isso podemos concluir que fungos e bactérias são os microrganismos entomopatogênicos mais utilizados na formulação de biopesticidas, sendo as espécies Metarhizium anisopliae, Beauveria bassiana e Bacillus thuringiensis as espécies mais utilizadas. Destas últimas, sua eficácia biocida baseia-se na ação da proteína Cry e, das primeiras, sua eficácia depende da adesão do esporo à cutícula do inseto praga.

Palavras-chave: Controle biológico; Entomopatogênico; Adhesin; Toxina cry.
\end{abstract}

\title{
1. Introducción
}

Los bioplaguicidas son la alternativa saludable para controlar las plagas de los cultivos agrícolas, por el hecho de que sus formulaciones están compuestas por organismos vivos completos, sus partes o productos proteicos. Estos organismos vivos son también llamados agentes de control biológico, entre los que figuran las bacterias, los hongos, los parásitos y los virus (Ibarra, 2006).

Los bioplaguicidas compuestos con hongos entomopatógenos más utilizados son los que contienen a los hongos microscópicos de los géneros Metarhizium y Beauveria (Butt et al., 2016) ya que estos dos géneros presentan diferentes formas de acción que no solo actúan eliminado al insecto plaga sino también estableciendo relaciones benéficas con las plantas (Litwin et al., 2020). Diversas investigaciones han demostrado que los hongos entomopatógenos a diferencia de las bacterias y virus infectan a los insectos por penetración directa de la cutícula (Bilgo et al., 2018), en la cual se evidencia en un primer momento la acción de fuerzas hidrófobas y electrostáticas seguido de una actividad dirigida por hidrofobinas (Skinner et al., 2014).

Adicionalmente, podemos mencionar que, si bien los hongos se demoran en relación al uso de químicos entre una a tres semanas para eliminar al insecto plaga, su efectividad como controlador biológico se expresa desde el momento en que infecta al insecto ya que este deja de alimentarse de la planta (Pucheta et al., 2006).

Por otro lado, los bioplaguicidas basados en bacterias, en especial aquellos compuestos por Bacillus thuringiensis, se encuentran representando aproximadamente el 90\% del mercado de bioplaguicidas (Sanchis y Bourguet, 2009), debido a que B. thuringiensis presenta una actividad larvicida rápida pero sostenida, además es de fácil aplicación ya que se emplea equipos estándar y por si fuera poco sus efectos sobre los insectos benéficos y organismos no objetivos son insignificantes (VillarrealDelgado et al., 2018).

Los bioplaguicidas con B. thuringiensis, deben su efectividad a la acción que ejerce la proteína Cry, la cual es sintetizada por la bacteria durante su proceso de esporulación, la misma que es toxica para distintas larvas de insectos (Lacey et al., 2015).

Teniendo en consideración todo lo antes mencionado podemos afirmar que la principal fortaleza de los bioplaguicidas está basada en los diferentes mecanismos de acción que ejercen estos microorganismos sobre los insectos plagas. Motivo por el cual en la presente revisión se realiza una descripción de la acción biocida que ejercen los hongos y bacterias entomopatógenas, por ser estos los agentes de control biológico más empleados en las formulaciones de los bioplaguicidas comerciales

\section{Metodología}


Esta investigación es una revisión de literatura narrativa (Rother, 2007). Se seleccionaron 63 artículos científicos de investigación en entomopatógenos, en donde: i) 20 corresponden a temas desde un enfoque genético (genes de virulencia), ii) 23 artículos detallan los mecanismos de acción por hongos entomopatógenos, iii) 08 explican los mecanismos de acción que ejerce la bacteria Bacillus thuringiensis y iv) 12 artículos sobre características de los bioinsecticidas microbianos comerciales. Para tal efecto se eligieron artículos publicados entre los años 1981 al 2021, en los que se incluyeron artículos de investigación que evidencian actividades de bioplaguicidas, de los que se excluyeron los trabajos de finalización del curso, monografías, disertaciones y tesis.

\section{Resultados y Discusión}

\subsection{Mecanismo de acción de hongos entomopatógenos}

Diversas investigaciones han demostrado que los mecanismos de acción insecticida de los hongos a diferencia de bacterias y virus, inicia cuando el hongo infecta a los insectos por penetración directa sobre la cutícula (Bilgo et al., 2018), en la cual participan diversas enzimas así como la acción de fuerzas hidrófobas y electrostáticas seguido de una actividad dirigida por hidrofobinas (Skinner et al., 2014). (ver Figuras 1 y 2).

Figura 1. Investigaciones relacionadas con los mecanismos de acción de los hongos entomopatógenos descritos en la literatura.

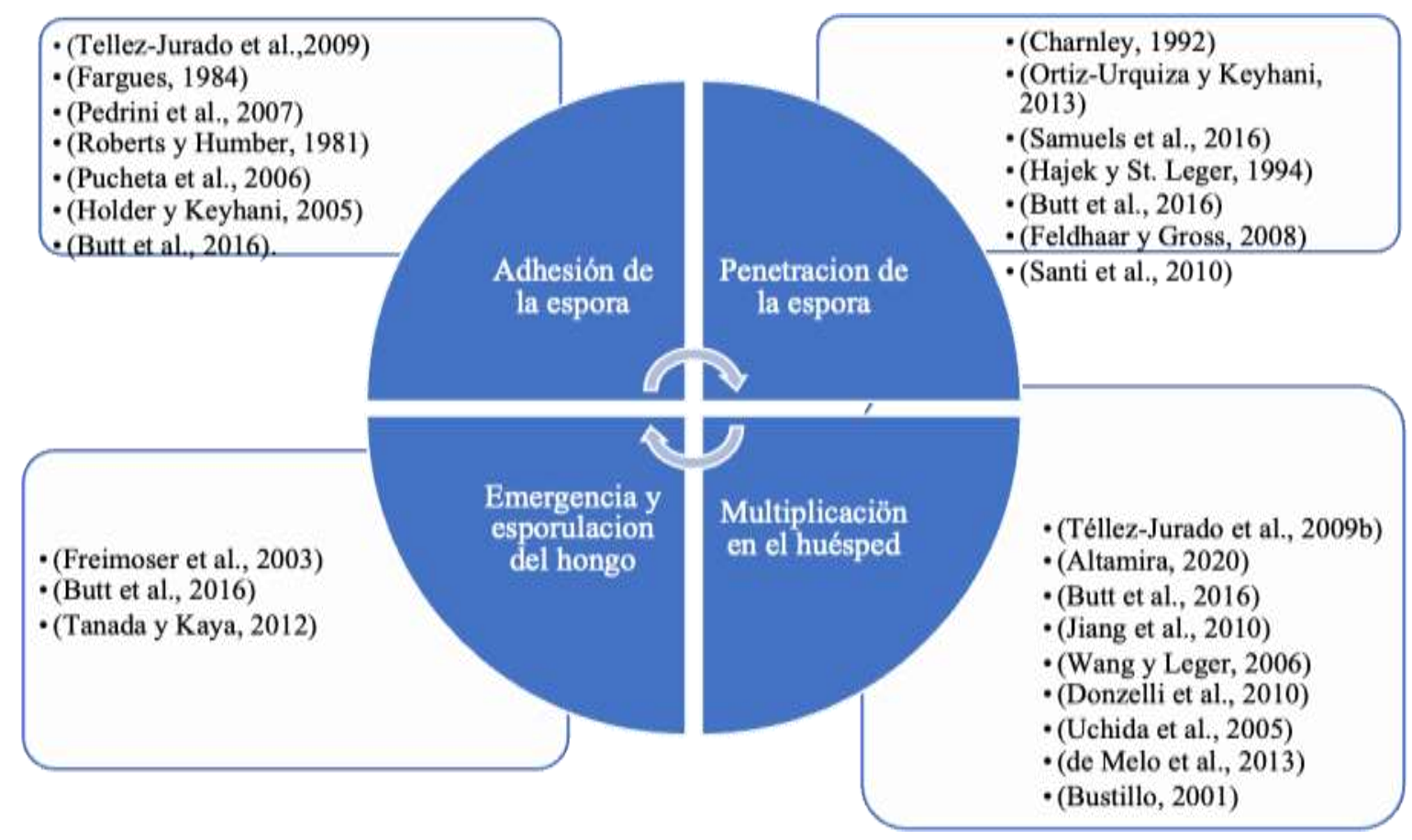

Fuente: Autores.

\subsubsection{Adhesión de la espora}

La adhesión de los hongos entomopatógenos sobre la cutícula de los insectos implica mecanismos tanto físicos como químicos (Fargues, 1984). Es así, que todo inicia cuando la espora se deposita en la superficie del insecto (Téllez-Jurado et al., 2009), para luego continuar con la adsorción de la espora, en el cual se da el reconocimiento de receptores específicos (glicoproteínas) en el insecto (Pedrini et al., 2007), seguido de la activación de enzimas por parte del huésped como del hongo (Roberts y Humber, 1981) para luego germinar y formar el apresorio (Pucheta et al., 2006). 
Por otro lado, es importante señalar que cuando sucede la adhesión de la espora del hongo en la cutícula, participan proteínas tipo adhesinas las que son sintetizadas por el hongo (Holder y Keyhani, 2005). Finalmente, cabe resaltar que la etapa de adhesión es un condicionante importante, ya que el éxito de la muerte del insecto depende del número de esporas que se adhieren a la cutícula (Butt et al., 2016).

\subsubsection{Penetración de la espora}

Existen características de la cutícula del huésped, que condicionan este proceso como son el grosor, la esclerotización y la presencia de sustancias antifúngicas y nutricionales (Charnley, 1992). Así mismo esta cutícula es rica en lípidos, quitina y proteínas esclerotizadas (Ortiz-Urquiza y Keyhani, 2013). Terminado la adhesión de la espora (Figura 2), se inicia la fase de penetración, con la degradación de la cutícula, por acción de enzimas que se sitúan en el apresorio (Samuels et al., 2016), ello conlleva a la ruptura de la cutícula, para luego continuar con la penetración de las hifas a través de la rajaduras (Hajek y St. Leger, 1994). Durante esta etapa de la penetración además de actuar enzimas hidrolíticas también participan moléculas que inhabilitan las respuestas inmunitarias del huésped (Butt et al., 2016); sin embrago, el huésped puede expresar su defensa con antimicrobianos, entre péptidos y especies reactivas de oxígeno, que muchas veces puede suprimir al hongo (Feldhaar y Gross, 2008). Por otro lado, para que el hongo finalmente ingrese al hemocele e infecte sus tejidos, este secreta fosfolipasa $\mathrm{C}$ para hidrolizar los enlaces fosfodiéster que se encuentran en la membrana celular del huésped (Santi et al., 2010). Por último, es importante señalar que las diferentes enzimas y moléculas están codificadas por genes, los mismos que se presentan en la Tabla 1.

Figura 2. Etapas que ilustran el mecanismo de acción de los hongos entomopatógenos: a. Adhesión, la espora se deposita en la superficie del insecto y allí participan proteínas “adhesinas” producidas por el hongo; b. Penetración, formación del apresorio y ruptura de la cutícula y penetración de hifas al hemocele; c. Multiplicación, transformación de la forma micelial a levaduriforme, bajo la cual se multiplica, absorbe nutrientes, provoca cambios fisiológicos y la muerte del insecto; d. Emergencia y esporulación, el hongo vuelve a su forma micelial, emerge del insecto y esporula.

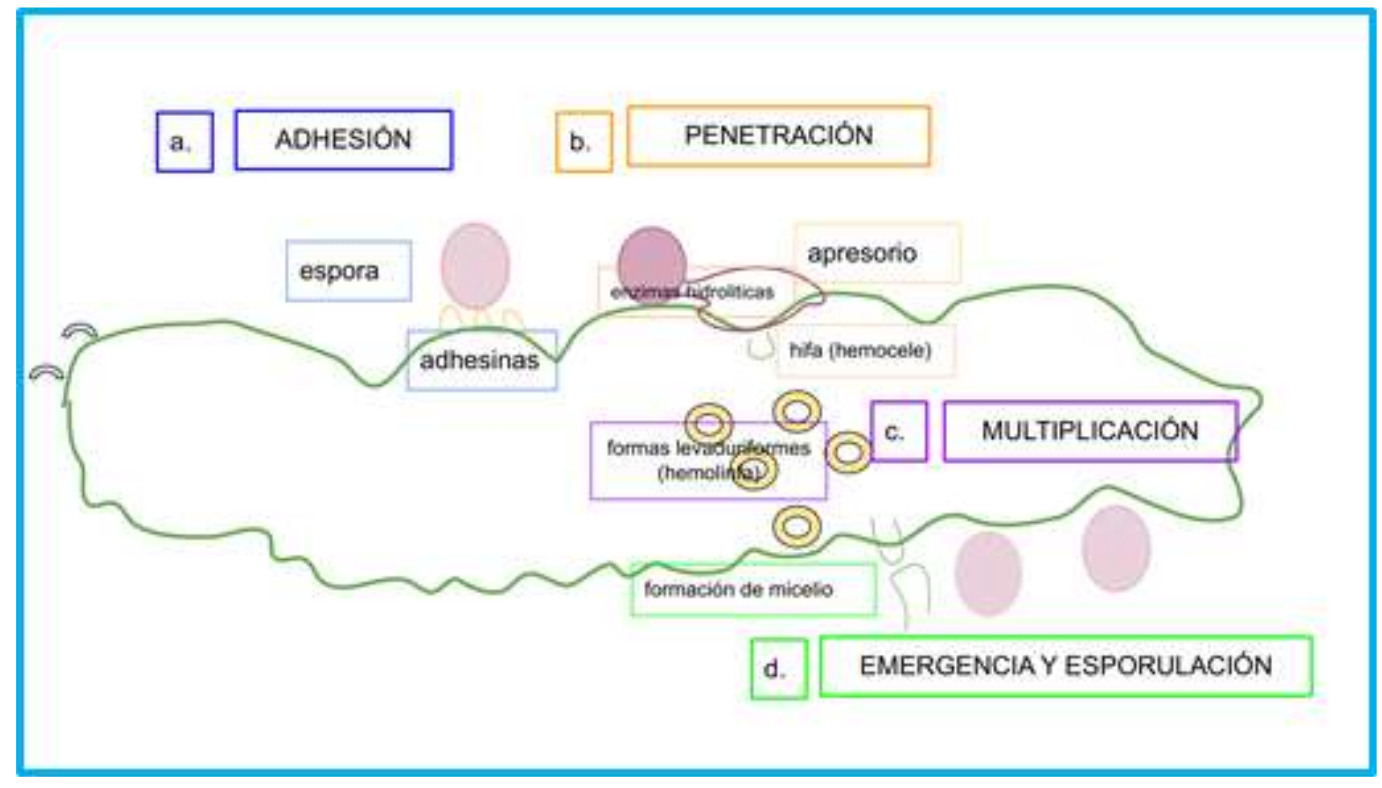

Fuente: Autores. 
Tabla 1. Genes que se expresan en los mecanismos de acción de hongos y bacterias entomopatógenas.

\begin{tabular}{|c|c|c|c|c|}
\hline Función entomopatógena & $\begin{array}{l}\text { Genes de } \\
\text { virulencia }\end{array}$ & $\begin{array}{l}\text { Función de las } \\
\text { Proteínas }\end{array}$ & Especie & Citas bibliográficas \\
\hline \multirow{4}{*}{ Adhesión a la cutícula } & MAD1, MAD2 & Adhesinas & $\begin{array}{l}\text { Metarhizium anisopliae, } \\
\text { Metarhizium brunneum, } \\
\text { Beauveria bassiana }\end{array}$ & (Shang et al., 2015) \\
\hline & $\begin{array}{l}\text { Hyd1, Hyd2, } \\
\text { Hyd3 }\end{array}$ & Hidrofobinas & $\begin{array}{l}\text { Beauveria bassiana, } \\
\text { Metarhizium brunneum }\end{array}$ & (Sevim et al., 2012) \\
\hline & SsgA & Hidrofobinas & Metarhizium anisopliae & (Li et al., 2010) \\
\hline & CWP10 & $\begin{array}{l}\text { Incrementa la } \\
\text { hidrofobicidad de } \\
\text { las esporas }\end{array}$ & Metarhizium anisopliae & (Li et al., 2010) \\
\hline \multirow{3}{*}{ Degradación de cutícula } & $\operatorname{Pr} 1, \operatorname{Pr} 2, \operatorname{Pr} 4$ & $\begin{array}{l}\text { Subtilisina, } \\
\text { tripsina, cisteína } \\
\text { proteasa }\end{array}$ & Metarhizium anisopliae & $\begin{array}{l}\text { (Rosas-García et al., 2014; } \\
\text { Wang et al., 2002) }\end{array}$ \\
\hline & $\begin{array}{l}\text { Bbchit1, } \\
\text { Bbchit2 }\end{array}$ & Quitinasas & Beauveria bassiana & (Fang et al., 2005) \\
\hline & Vlchit1 & Quitinasas & Verticillium lecanii & (Zhu et al., 2008) \\
\hline \multirow[t]{2}{*}{ Manejo del estrés } & $\begin{array}{l}\text { HSP25, HSP30, } \\
\text { HSP70, } \\
\text { HSP90 }\end{array}$ & $\begin{array}{l}\text { Proteínas de shock } \\
\text { térmico }\end{array}$ & Beauveria bassiana & $\begin{array}{l}\text { (Zhou et al., 2018; Wang } \\
\text { et al., 2020) }\end{array}$ \\
\hline & Hog1, Pmr1 & $\begin{array}{l}\text { Quinasa activada } \\
\text { por mitógeno }\end{array}$ & Beauveria bassiana & (Zhang et al., 2009) \\
\hline \multirow{3}{*}{$\begin{array}{l}\text { Adaptación a la hemolinfa/ } \\
\text { inmunomodulación }\end{array}$} & Mos1 & Osmosensor & Beauveria bassiana & (Lee et al., 2018) \\
\hline & Mcl1 & Colágeno & $\begin{array}{l}\text { Metarhizium brunneum } \\
\text { Metarhizium acridum } \\
\text { Metarhizium robertsii }\end{array}$ & $\begin{array}{l}\text { (Aw y Hue, 2017; Xie et al., } \\
\text { 2019) }\end{array}$ \\
\hline & Mr-npc2a & Carrier de esterol & Beauveria bassiana & (Sharma et al., 2020) \\
\hline \multirow{3}{*}{$\begin{array}{l}\text { Multifactorial (Factores de } \\
\text { transcripción) }\end{array}$} & MrpacC & $\begin{array}{l}\text { Regula la } \\
\text { esporulación, la } \\
\text { penetración de } \\
\text { cutículas y la } \\
\text { evasión inmune }\end{array}$ & Metarhizium robertsii & (Huang et al., 2015) \\
\hline & MrSkn7 & $\begin{array}{l}\text { Controla la } \\
\text { esporulación, la } \\
\text { integridad de la } \\
\text { pared celular, la } \\
\text { autólisis y la } \\
\text { virulencia }\end{array}$ & Metarhizium robertsii & (Shang et al., 2015) \\
\hline & cag8 & $\begin{array}{l}\text { Involucrado en la } \\
\text { síntesis de } \\
\text { conidiación, } \\
\text { virulencia e } \\
\text { hidrofobina. }\end{array}$ & Metarhizium anisopliae & (Fang et al., 2007) \\
\hline \multirow[t]{2}{*}{ Formación de poro } & Cry & $\begin{array}{l}\text { Delta toxina } \\
\text { (proteína } \\
\text { paraesporal) }\end{array}$ & Bacillus thuringiensis & (Deng et al., 2014) \\
\hline & Vip & $\begin{array}{l}\text { Proteínas } \\
\text { insecticidas } \\
\text { vegetativas }\end{array}$ & Bacillus thuringiensis & (Güney et al., 2019) \\
\hline Receptor proteico de las toxinas & Cyt & $\begin{array}{l}\text { Proteínas } \\
\text { hemolíticas y } \\
\text { citolíticas }\end{array}$ & Bacillus thuringiensis & (Bravo et al., 2017) \\
\hline
\end{tabular}

Fuente: Autores.

\subsection{Multiplicación en el huésped}

Cuando el hongo llega al hemocele e invade la hemolinfa, muchos de ellos pasan de su forma micelial a la forma levaduriforme (Téllez-Jurado et al., 2009). Bajo esta forma se multiplica y con ella adquiere una gran ventaja, con respecto a superficie/volumen, en la absorción de nutrientes (Altamira, 2020). Sin embargo, ello provoca la expresión y secreción de 
receptores de reconocimiento de patógenos del insecto a nivel de la hemolinfa, superficie de hemocitos, cuerpo graso y membranas de las células epidérmicas (Butt et al., 2016). También a modo de defensa producen moléculas (lectinas, inhibidores de fenoloxidasa, péptidos antimicrobianos) y radicales reactivos de oxígeno y nitrógeno (Jiang et al., 2010). Por su parte, los hongos tratan de minimizar las defensas inmunes del huésped, a través de la producción de toxinas, cambios estructurales en su pared celular y resistencia a péptidos antimicrobianos (Wang y Leger, 2006). También se sabe de la existencia de metabolitos secundarios, que sirven para evitar la defensa del insecto y la propagación de oportunistas (Donzelli et al., 2010), actuando como inmunomoduladores (aumenta la producción de conidios) y antimicrobianos, entre los que figura las hidroxifungerinas (Uchida et al., 2005) y la miriocina (de Melo et al., 2013), los mismos que favorecen la permanencia eficaz del hongo (Altamira, 2020). Finalmente, la multiplicación del hongo provoca cambios fisiológicos anormales en el insecto sobreviniendo la muerte de este (Bustillo, 2001)

\subsection{Emergencia y esporulación}

Con la muerte del insecto, los nutrientes se agotan (fuentes de nitrógeno) ello provoca nuevamente que el hongo adquiera su forma micelial (Freimoser et al., 2003) y de esta forma emerge del insecto y en condiciones de humedad y temperatura se produce la esporulación en la superficie del cadáver (Butt et al., 2016). En secuencia sucede la dispersión de la espora y su adhesión en un nuevo huésped (Tanada y Kaya, 2012)

Figura 3. Etapas del mecanismo de acción de Bacillus thuringiensis en la larva del insecto: a. Ingestión de las esporas y delta endotoxinas, tanto la espora como la delta endotoxina (Cry) llegan al intestino medio; b. Solubilización de la delta endotoxina, liberación en forma de protoxinas en $\mathrm{pH}$ alcalino; c. Activación de la toxina, por acción de proteasas del intestino la cual provoca la liberación del fragmento tóxico; d. Unión de la toxina al receptor transmembrana, la toxina se une al receptor transmembranal "caderina", ingresa a través de ella, lo cual provoca la formación de un poro lítico, gracias al cual se da un desequilibrio osmótico; e. Germinación de la espora, bajo esta forma invade en su totalidad al insecto provocando septicemia y daño en los tejidos

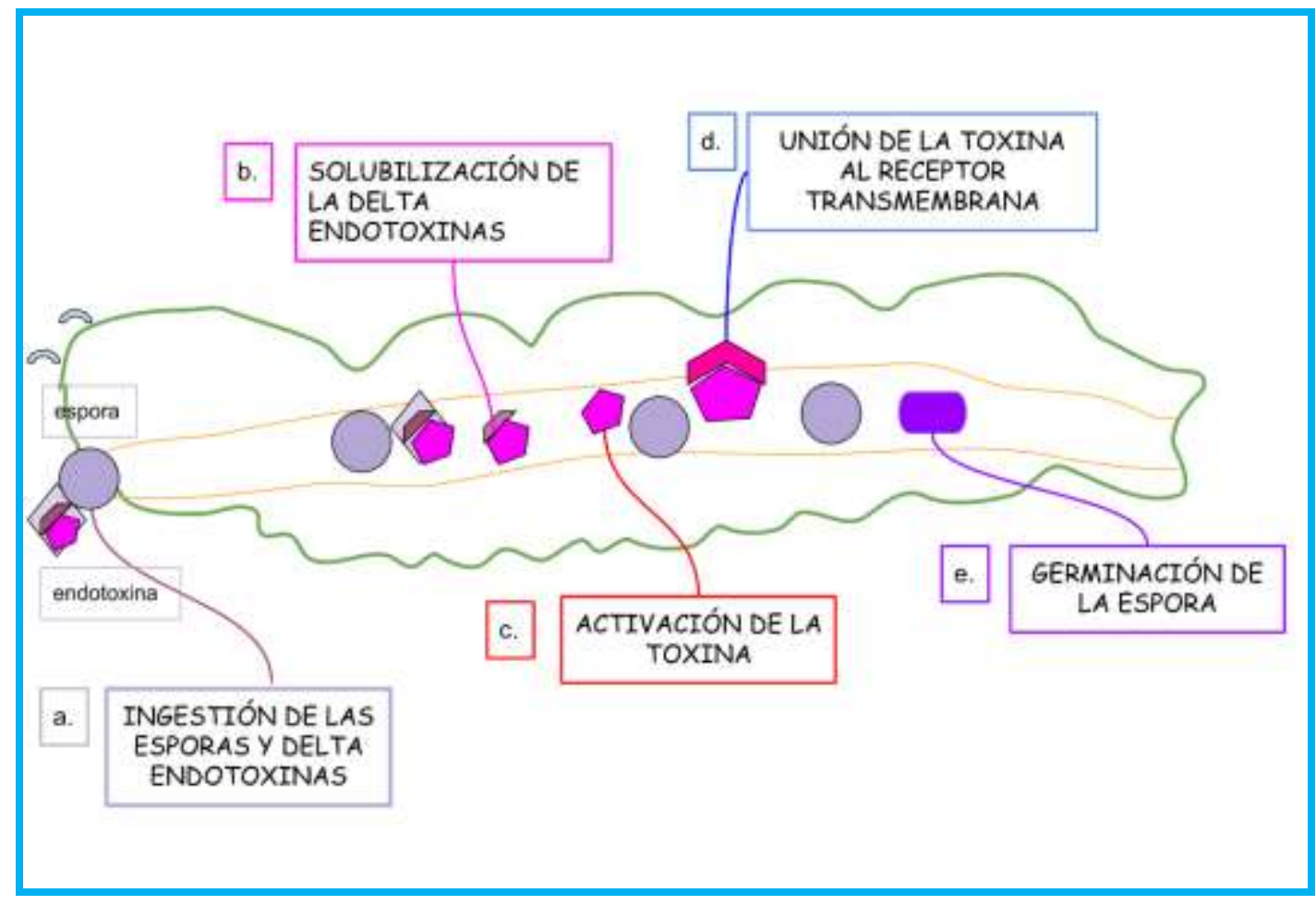

Fuente: Autores. 


\subsection{Mecanismo de acción de Bacillus thuringiensis}

Bacillus thuringiensis es una bacteria entomopatógena, con forma de bastón, Gram positiva, formadora de esporas se encuentra generalmente en el suelo, polvo, insectos muertos y agua (Hernandez-Fernandez, 2016). B. thuringiensis, es la más usada en la formulación de biopesticidas (López-Pazos y Cerón, 2010) gracias a su alta especificidad, a su mínima incidencia de fenómenos de resistencia y por no afectar o dañar al hombre (Lacey et al., 2015) ni a la entomofauna benéfica del ambiente (Schnepf et al., 1998). Otra de las razones importantes por las cuales es la más empleada en la formulación de biopesticidas, es que $B$. thuringiensis posee una inclusión paraesporal de naturaleza proteica que resulta ser tóxico para las larvas de insectos plagas (Xu et al., 2014), conocida como proteína Cry .(Figura 3).

Figura 4. Resumen del mecanismo de acción de Bacillus thuringiensis en el insecto.

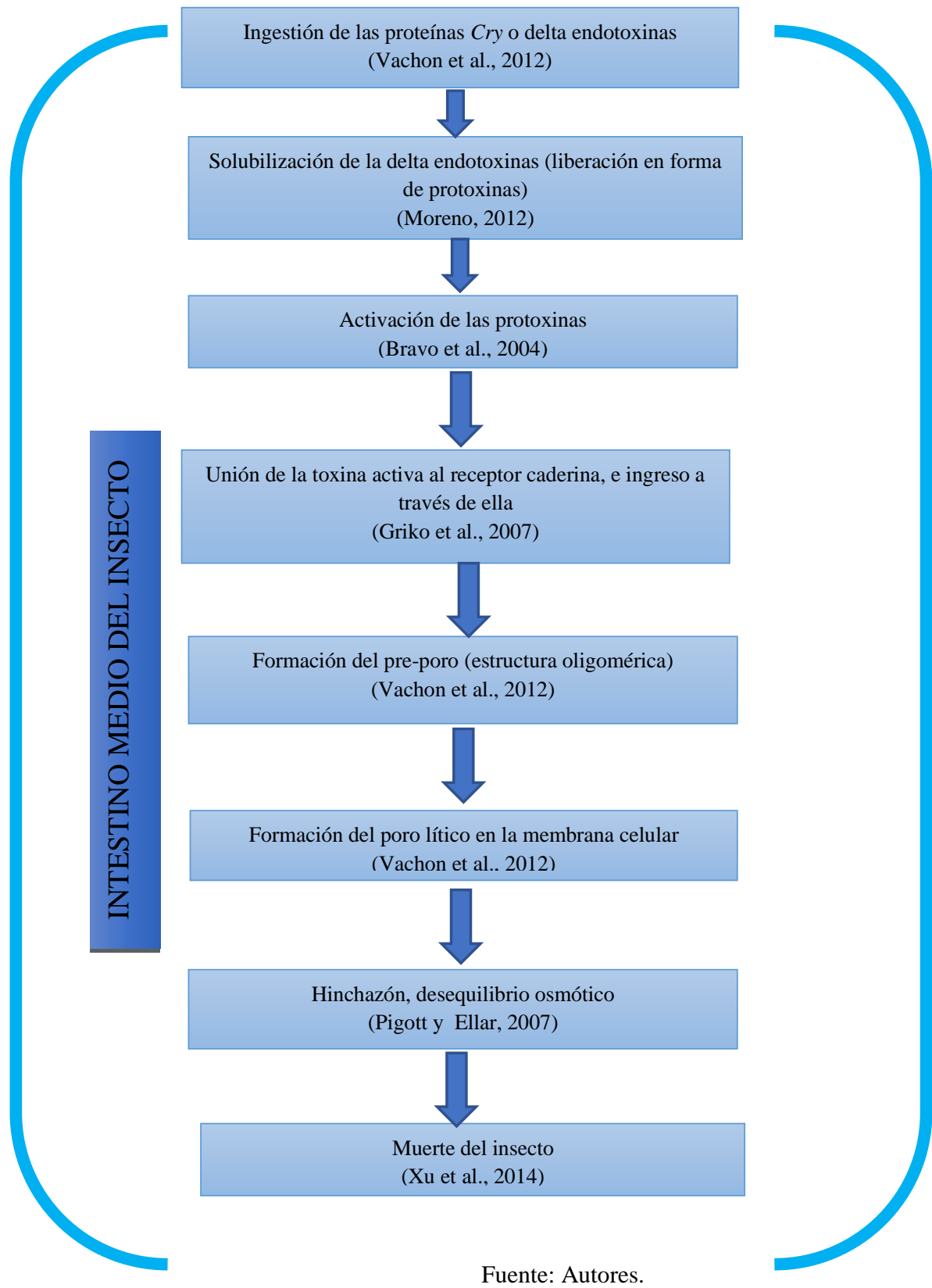

El mecanismo de acción insecticida de B. thuringiensis (Figura 3), inicia cuando las proteínas Cry o delta endotoxinas son ingeridos por las larvas (Vachon et al., 2012). Ya en el intestino medio de la larva estas delta endotoxinas son solubilizadas 
(liberación en forma de protoxinas) gracias al pH alcalino que existe (Moreno, 2012), seguidamente sucede la activación de las protoxinas provocada por proteasas del intestino, estas cortan la protoxina liberándose de esta manera el fragmento tóxico, las mismas que serán las responsables de la muerte del insecto (Bravo et al., 2004), esta toxina activa se une al receptor caderina (proteína transmembranal), localizado a nivel de la microvellosidades (Griko et al., 2007), e ingresa a través de ella e inmediatamente se da una cascada de señalización provocando la formación de una estructura oligomérica, primero como un pre-poro para terminar en un poro lítico (Vachon et al., 2012) a través del cual ocurre el paso de iones y agua, lo que provoca hinchazón y desequilibrio osmótico (Pigott y Ellar, 2007). Finalmente sucede la muerte del insecto debido a que se dan condiciones para la germinación de las esporas y de esta forma B. thuringiensis invade en su totalidad al huésped provocando septicemia y daño en los tejidos (Figura 4) (Xu et al., 2014).

\subsection{Importancia de los microorganismos nativos entomopatógenos en la fabricación de bioinsecticidas comerciales}

Aun cuando se sabe que los bioinsecticidas pueden demostrar eficacia y cuidar el ambiente, su comercialización es muy baja con respecto a los insecticidas químicos, en el Perú por ejemplo, del total de productos registrados para control de plagas (Tabla 2), en el año 2019, solo un 20\% aproximadamente corresponde a bioplaguicidas (SENASA, 2021). Esta demanda es limitada ya que muchas de las formulaciones no mantienen su viabilidad y virulencia (Moreno, 2012) debido a que los agentes biológicos con los que han sido formulados se ven afectados por los factores abióticos (temperatura, radiación UV, humedad) en donde son aplicados (Fernández y Juncosa, 2002). Es así, que los bioinsecticidas demuestran alta efectividad en ambientes similares al lugar del que fueron obtenidos (Muñoz, 2018). Por ello es importante, el desarrollo de bioinsecticidas que incluya formulaciones con principios activos (microorganismos) propios (nativos) del lugar donde va ser aplicado, para una mayor efectividad.

Tabla 2. Bioinsecticidas microbianos comerciales distribuidos en Perú.

\begin{tabular}{|c|c|c|c|c|c|c|}
\hline $\begin{array}{l}\text { Nombre } \\
\text { comercial }\end{array}$ & $\begin{array}{l}\text { Empresa } \\
\text { Biotecnológica } \\
\text { /país de origen }\end{array}$ & Ingrediente activo & Concentración & Especificidad & Cultivos de aplicación & Dosis \\
\hline TURINCOL® & $\begin{array}{l}\text { FUNGICOL DEL } \\
\text { PERU S.A.C / } \\
\text { PERU }\end{array}$ & $\begin{array}{l}\text { Bacillus thuringiensis } \\
\text { var. Kurstaki. }\end{array}$ & $\begin{array}{l}32.000 .000 \\
\text { unidades } \\
\text { internacionales } \\
\text { por } \mathrm{cm}^{3} \text { de } \\
\text { producto } \\
\text { formulado. }\end{array}$ & $\begin{array}{l}\text { Larvas de insectos } \\
\text { del orden } \\
\text { Lepidóptera de } \\
\text { primero y segundo } \\
\text { instar. }\end{array}$ & $\begin{array}{l}\text { Col, coliflor, brócoli, } \\
\text { melón, pepino, sandia, } \\
\text { caña de azúcar, sorgo, } \\
\text { maíz, alfalfa, papa, frijol, } \\
\text { fresa, palma, tomate, } \\
\text { tabaco, ajonjolí }\end{array}$ & $\begin{array}{l}250 \text { a } 500 \mathrm{~cm}^{3} \text { por } \\
\text { cada } 200 \text { litros de } \\
\text { agua }\end{array}$ \\
\hline INSECBIOL & $\begin{array}{l}\text { FUNGICOL DEL } \\
\text { PERU S.A.C / } \\
\text { PERU }\end{array}$ & $\begin{array}{l}\text { Metarhizium } \\
\text { anisopliae } \\
\text { Beauveria bassiana } \\
\text { Paecilomyces lilacinus } \\
\text { Paecilomyces } \\
\text { fumosoroseus }\end{array}$ & $\begin{array}{l}1 \times 10^{8} \mathrm{UFC} / \mathrm{g} \\
\text { de producto }\end{array}$ & $\begin{array}{l}\text { Diferentes plagas } \\
\text { chupadoras, } \\
\text { desfoliadores, } \\
\text { picudos }\end{array}$ & $\begin{array}{l}\text { Palma, arroz, café, caña } \\
\text { de azúcar, flores, } \\
\text { plátano, cítricos }\end{array}$ & $\begin{array}{l}1.000 \mathrm{~g} / \mathrm{ha} \text { por } \\
\text { aplicación }\end{array}$ \\
\hline BAUBASSIL@ & $\begin{array}{l}\text { FUNGICOL DEL } \\
\text { PERU S.A.C / } \\
\text { PERU }\end{array}$ & Beauveria bassiana. & $\begin{array}{l}100 \text { millones } \\
\left(1 \times 10^{8}\right) \text { de } \\
\text { esporas o } \\
\text { conidios / } \\
\text { gramo de } \\
\text { formulación }\end{array}$ & $\begin{array}{l}\text { Broca del café, } \\
\text { Picudo negro del } \\
\text { Plátano, Picudo } \\
\text { verde-azul de los } \\
\text { cítricos y } \\
\text { Taladrador de la } \\
\text { caña }\end{array}$ & $\begin{array}{l}\text { Algodón, arracacha, } \\
\text { papa, plátano, café } \\
\text { flores, piñas, pastos, } \\
\text { arroz, palma, frutales y } \\
\text { hortalizas }\end{array}$ & $\begin{array}{l}\text { Aplicaciones } \\
\text { foliares: Usar de } \\
250 \text { a } 500 \\
\text { g/cilindro. } \\
\text { Aplicaciones } \\
\text { edáficas usar 1,000 } \\
\text { g/ha }\end{array}$ \\
\hline METARIL $^{\text {h }}$ & $\begin{array}{l}\text { FUNGICOL DEL } \\
\text { PERU S.A.C / } \\
\text { PERU }\end{array}$ & $\begin{array}{l}\text { Metarhizium } \\
\text { anisopliae }\end{array}$ & $\begin{array}{l}\text { 1x10 esporas / } \\
\text { gramo de } \\
\text { producto } \\
\text { formulado. }\end{array}$ & $\begin{array}{l}\text { Chinches, gallinita } \\
\text { ciega, } \\
\text { barrenadores, } \\
\text { grillos y picudos } \\
\text { principalmente }\end{array}$ & $\begin{array}{l}\text { Diferentes Cultivos } \\
\text { agrícolas }\end{array}$ & $\begin{array}{l}\text { Aplicación edáfica } \\
\text { a razón de } 1.000 \\
\text { g/ha. } \\
\text { Aplicación foliar a } \\
\text { razón de } 250 \text { a } 500 \\
\text { g/cilindro }\end{array}$ \\
\hline
\end{tabular}




\begin{tabular}{|c|c|c|c|c|c|c|}
\hline FUMOSIL $^{\text {h }}$ & $\begin{array}{l}\text { FUNGICOL DEL } \\
\text { PERU S.A.C / } \\
\text { PERU }\end{array}$ & $\begin{array}{l}\text { Paecilomyces } \\
\text { fumosoroseus o Isaria } \\
\text { fumosorosea }\end{array}$ & $\begin{array}{l}\text { 1x10 esporas / } \\
\text { gramo de } \\
\text { producto } \\
\text { formulado }\end{array}$ & $\begin{array}{l}\text { Mosca blanca, } \\
\text { cochinillas, } \\
\text { minadores, } \\
\text { pulgones; trips }\end{array}$ & $\begin{array}{l}\text { Diferentes Cultivos } \\
\text { agrícolas }\end{array}$ & $\begin{array}{l}\text { Para aplicaciones } \\
\text { edáficas usar } 1.000 \\
\mathrm{~g} / \mathrm{ha} . \\
\text { Para aplicaciones } \\
\text { foliares usar } 250- \\
500 \mathrm{~g} / \text { cilindro de } \\
200 \text { litros de agua. }\end{array}$ \\
\hline BAZTHU-32 & $\begin{array}{l}\text { LAINCO, S.A / } \\
\text { ESPAÑA }\end{array}$ & $\begin{array}{l}\text { Bacillus thuringiensis } \\
\text { var. Kurstaki. }\end{array}$ & $\begin{array}{l}32 \text { millones de } \\
\text { U.I./g }\end{array}$ & $\begin{array}{l}\text { Larvas de } \\
\text { lepidópteros }\end{array}$ & $\begin{array}{l}\text { Algodón, cítricos, } \\
\text { forestales, fresa, } \\
\text { hortícolas, manzano, } \\
\text { olivo y tomate }\end{array}$ & $\begin{array}{l}0,25-0,5 \mathrm{Kg} / \mathrm{ha} \\
\text { recubriendo bien } \\
\text { toda la vegetación }\end{array}$ \\
\hline TUREX & $\begin{array}{l}\text { CERTIS } \\
\text { EUROPE / } \\
\text { ESPAÑA }\end{array}$ & $\begin{array}{l}\text { Bacillus thuringiensis } \\
\text { Aizawai }+ \text { Kurstaki }\end{array}$ & $\begin{array}{l}25 \text { millones } \\
\text { U.I./g }\end{array}$ & $\begin{array}{l}\text { Orugas } \\
\text { defoliadoras }\end{array}$ & $\begin{array}{l}\text { Lechuga, hortalizas del } \\
\text { género Brassica, olivo, } \\
\text { pimiento, tomate y vid }\end{array}$ & $\begin{array}{l}1-2 \mathrm{Kg} / \mathrm{ha} \\
\mathrm{O} \\
1,5-2 \mathrm{Kg} / \mathrm{ha}\end{array}$ \\
\hline DELFIN & $\begin{array}{l}\text { CERTIS } \\
\text { EUROPE / } \\
\text { ESPAÑA }\end{array}$ & $\begin{array}{l}\text { Bacillus thuringiensis } \\
\text { Kurstaki cepa SA-1. }\end{array}$ & $\begin{array}{l}32 \text { millones de } \\
\text { U.I./gr }\end{array}$ & $\begin{array}{l}\text { larvas de } \\
\text { lepidópteros }\end{array}$ & $\begin{array}{l}\text { Hortícolas, fresales, } \\
\text { cítricos, olivo, vid y } \\
\text { algodonero }\end{array}$ & $0,5-0,750 \mathrm{~kg} / \mathrm{ha}$ \\
\hline FUMOGAN & $\begin{array}{l}\text { SOLAGRO / } \\
\text { PERU }\end{array}$ & Isaria fumosorosea & $\begin{array}{l}1 \times 10^{12} \\
\text { conidios/kg }\end{array}$ & $\begin{array}{l}\text { orden Díptera, } \\
\text { Lepidóptero, } \\
\text { Coleóptera, } \\
\text { Hemíptera y } \\
\text { Homóptero }\end{array}$ & $\begin{array}{l}\text { Palto, arándano, } \\
\text { esparrago, pimientos, vid } \\
\text { y cítricos }\end{array}$ & $\begin{array}{l}\text { Dosis /200L } \\
1.6-4 \mathrm{Kg}\end{array}$ \\
\hline BEAUVESOL & $\begin{array}{l}\text { SOLAGRO / } \\
\text { PERU }\end{array}$ & Beauveria bassiana & $\begin{array}{l}1 \times 10^{12} \\
\text { conidios/kg }\end{array}$ & $\begin{array}{l}\text { Lepidóptera, } \\
\text { Hemíptera, } \\
\text { Coleóptera, } \\
\text { Ortóptera y } \\
\text { Homóptera }\end{array}$ & $\begin{array}{l}\text { Arándano, Café/Cacao, } \\
\text { tomate, tabaco, flores, } \\
\text { cítricos, frijol, soya, } \\
\text { cucurbitáceas, melón, } \\
\text { pepino, sandia, } \\
\text { berenjena, ajíes, fresas, } \\
\text { frambuesas y palto }\end{array}$ & $10 \mathrm{Kg} / \mathrm{ha}$ \\
\hline Micosplag® & $\begin{array}{l}\text { SERFI S.A. I } \\
\text { PERU }\end{array}$ & $\begin{array}{l}\text { Beauveria bassiana, } \\
\text { Metarhizium } \\
\text { anisopliae y } \\
\text { Purpureocillium } \\
\text { lilacinum }\end{array}$ & $\begin{array}{l}1 \times 10^{8} \\
\text { esporas/g de } \\
\text { producto }\end{array}$ & $\begin{array}{l}\text { Mosquilla del } \\
\text { brote }\end{array}$ & Espárrago & $200 \mathrm{~g} / \mathrm{ha}$ \\
\hline Bt-2X® & $\begin{array}{l}\text { SERFI S.A. / } \\
\text { PERU }\end{array}$ & $\begin{array}{l}\text { Bacillus thuringiensis } \\
\text { var. Kurstaki }\end{array}$ & $32000 \mathrm{UI} / \mathrm{mg}$ & $\begin{array}{l}\text { Gusano de Hoja, } \\
\text { gusano perforador } \\
\text { de la bellota, } \\
\text { gusano medidor, } \\
\text { gusano comedor, } \\
\text { cogollero, } \\
\text { comedor de } \\
\text { follaje, gusano } \\
\text { perforador de } \\
\text { frutos, gusano del } \\
\text { cesto. }\end{array}$ & $\begin{array}{l}\text { Algodón, arándano, } \\
\text { frejol, col, maíz, } \\
\text { espárrago, mandarina, } \\
\text { palto y pecano }\end{array}$ & $0.3-0.5 \mathrm{Kg} / \mathrm{ha}$ \\
\hline
\end{tabular}

Fuente: Los autores.

\section{Conclusiones}

Los hongos y bacterias son los microorganismos más empleados en la formulación de los bioplaguicidas, con respecto a los hongos las especies que más resaltan son Metarhizium anisopliae y Beauveria bassiana, en representación de las bacterias la especie más utilizada es Bacillus thuringiensis. De este último su efectividad insecticida se fundamenta en la acción de la proteína Cry y de los primeros su efectividad depende de la adhesión de la espora a la cutícula del insecto.

Estos resultados sugieren que el uso de bioplaguicidas continúa siendo una importante herramienta en el control de plagas de los principales cultivos de interés agrícola. Así mismo, que el conocimiento de las diferentes formas y formulados de los productos de bacterias y hongos que están disponibles en el mercado, mejoran la efectividad de las estrategias de control. Es por ahí la importancia de trabajos como éste, que reúnen y precisan toda esta información. 


\section{Referencias}

Altamira, P. (2020). Microorganismos con actividad entomopatogena. Boletin INIA-Instituto de Investigaciones Agropecuarias. https://biblioteca.inia.cl/handle/123456789/6899

Aw, K. M. S. \& Hue, S. M. (2017). Mode of Infection of Metarhizium spp. Fungus and Their Potential as Biological Control Agents. Journal of Fungi, 3(2), 30. https://doi.org/10.3390/jof3020030

Baratto, C. M., Dutra, V., Boldo, J. T., Leiria, L. B., Vainstein, M. H. \& Schrank, A. (2006). Isolation, Characterization, and Transcriptional Analysis of the Chitinase chi2 Gene (DQ011663) from the Biocontrol Fungus Metarhizium anisopliae var. Anisopliae. Current Microbiology, 53(3), 217-221. https://doi.org/10.1007/s00284-006-0078-6

Bilgo, E., Lovett, B., St. Leger, R. J., Sanon, A., Dabiré, R. K \& Diabaté, A. (2018). Native entomopathogenic Metarhizium spp. From Burkina Faso and their virulence against the malaria vector Anopheles coluzzii and non-target insects. Parasites \& Vectors, 11(1), 209. https://doi.org/10.1186/s13071-018-2796-6

Bravo, A., Gómez, I., Conde, J., Muñoz-Garay, C., Sánchez, J., Miranda, R., Zhuang, M., Gill, S. S. \& Soberón, M. (2004). Oligomerization triggers binding of a Bacillus thuringiensis Cry1Ab pore-forming toxin to aminopeptidase $\mathrm{N}$ receptor leading to insertion into membrane microdomains. Biochimica et Biophysica Acta (BBA) - Biomembranes, 1667(1), 38-46. https://doi.org/10.1016/j.bbamem.2004.08.013

Bravo, Pacheco, S., Gómez, I., Garcia-Gómez, B., Onofre, J. \& Soberón, M. (2017). Insecticidal Proteins from Bacillus thuringiensis and Their Mechanism of Action. En L. M. Fiuza, R. A. Polanczyk y N. Crickmore (Eds.), Bacillus thuringiensis and Lysinibacillus sphaericus: Characterization and use in the field of biocontrol (pp. 53-66). Springer International Publishing. https://doi.org/10.1007/978-3-319-56678-8_4

Bustillo, A. (2001). Hongos e insectos y posibilidades de uso de control biológico de plagas en colombia. seminario Uso de en tomopatógenos en Colombia. https://www.researchgate.net/publication/275462138_HONGOS_EN_INSECTOSy_POSIBILIDADES_DE_USO_EN_EL_CONTROL_BIOLOGICO_DE_P LAGAS_EN_COLOMBIA

Butt, T. M., Coates, C. J., Dubovskiy, I. M. \& Ratcliffe, N. A. (2016). Chapter Nine - Entomopathogenic Fungi: New Insights into Host-Pathogen Interactions. En B. Lovett y R. J. St. Leger (Eds.), Advances in Genetics, 94, 307-364. https://doi.org/10.1016/bs.adgen.2016.01.006

Charnley, A. K. (1992). Mechanisms of fungal pathogenesis in insects with particular reference to locusts. https://agris.fao.org/agrissearch/search.do?recordID=GB9124433

de Melo, N. R. de, Abdrahman, A., Greig, C., Mukherjee, K., Thornton, C., Ratcliffe, N. A., Vilcinskas, A. \& Butt, T. M. (2013). Myriocin Significantly Increases the Mortality of a Non-Mammalian Model Host during Candida Pathogenesis. PLOS ONE, 8(11), e78905. https://doi.org/10.1371/journal.pone.0078905

Deng, C., Peng, Q., Song, F. \& Lereclus, D. (2014). Regulation of cry Gene Expression in Bacillus thuringiensis. Toxins, 6(7), 2194-2209. https://doi.org/10.3390/toxins6072194

Donzelli, B. G. G., Krasnoff, S. B., Churchill, A. C. L., Vandenberg, J. D. \& Gibson, D. M. (2010). Identification of a hybrid PKS-NRPS required for the biosynthesis of NG-391 in Metarhizium robertsii. Current Genetics, 56(2), 151-162. https://doi.org/10.1007/s00294-010-0288-0

Fang, W., Leng, B., Xiao, Y., Jin, K., Ma, J., Fan, Y., Feng, J., Yang, X., Zhang, Y. \& Pei, Y. (2005). Cloning of Beauveria bassiana Chitinase Gene Bbchit1 and Its Application To Improve Fungal Strain Virulence. Applied and Environmental Microbiology, 71(1), 363-370. https://doi.org/10.1128/AEM.71.1.363370.2005

Fang, W., Pei, Y. \& Bidochka, M. (2007). A regulator of a G protein signalling (RGS) gene, cag8, from the insect-pathogenic fungus Metarhizium anisopliae is involved in conidiation, virulence and hydrophobin synthesis. Microbiology, 153, 1017-1025. https://doi.org/10.1099/mic.0.2006/002105-0

Fargues, J. (1984). Adhesion of the fungal spore to the insect cuticle in relation to pathogenicity. https://agris.fao.org/agrissearch/search.do?recordID $=$ US 8719800

Feldhaar, H. \& Gross, R. (2008). Immune reactions of insects on bacterial pathogens and mutualists. Microbes and Infection, 10(9), 1082-1088. https://doi.org/10.1016/j.micinf.2008.07.010

Fernández, C. \& Juncosa, R. (2002). Biopesticidas:¿ la agricultura del futuro. Phytoma, 141, 14-19. https://infoxica2.files.wordpress.com/2010/01/1-12biopesticidas-c2bf-la-agricultura-del-futuro.pdf

Freimoser, F. M., Grundschober, A., Tuor, U. \& Aebi, M. (2003). Regulation of hyphal growth and sporulation of the insect pathogenic fungus Entomophthora thripidum in vitro. FEMS Microbiology Letters, 222(2), 281-287. https://doi.org/10.1016/S0378-1097(03)00315-X

Griko, N. B., Rose-Young, L., Zhang, X., Carpenter, L., Candas, M., Ibrahim, M. A., Junker, M. \& Bulla, L. A. (2007). Univalent Binding of the Cry1Ab Toxin of Bacillus thuringiensis to a Conserved Structural Motif in the Cadherin Receptor BT-R1. Biochemistry, 46(35), 10001-10007. https://doi.org/10.1021/bi700769s

Güney, E., Adıgüzel, A., Demirbağ, Z. \& Sezen, K. (2019). Bacillus thuringiensis kurstaki strains produce vegetative insecticidal proteins (Vip 3) with high potential. Egyptian Journal of Biological Pest Control, 29(1), 81. https://doi.org/10.1186/s41938-019-0180-2

Hajek, A. E. \& St. Leger, R. J. (1994). Interactions Between Fungal Pathogens and Insect Hosts. Annual Review of Entomology, 39(1), 293-322. https://doi.org/10.1146/annurev.en.39.010194.001453

Hernandez-Fernandez, J. (2016). Bacillus thuringiensis: A natural tool in insect pest control. The handbook of microbial bioresources, 121-139. https://www.cabi.org/cabebooks/ebook/20163199951 
Holder, D. J. \& Keyhani, N. O. (2005). Adhesion of the Entomopathogenic Fungus Beauveria (Cordyceps) bassiana to Substrata. Applied and Environmental Microbiology, 71(9), 5260-5266. https://doi.org/10.1128/AEM.71.9.5260-5266.2005

Huang, W., Shang, Y., Chen, P., Gao, Q. \& Wang, C. (2015). MrpacC regulates sporulation, insect cuticle penetration and immune evasion in Metarhizium robertsii. Environmental Microbiology, 17(4), 994-1008. https://doi.org/10.1111/1462-2920.12451

Ibarra, J. E. (2006). Los microorganismos en el control biológico de insectos y fitopatógenos. Rev Latinoam Microbiol, 8 https://www.medigraphic.com/pdfs/lamicro/mi-2006/mi062k.pdf

Jiang, H., Vilcinskas, A. \& Kanost, M. R. (2010). Immunity in Lepidopteran Insects. En K. Söderhäll (Ed.), Invertebrate Immunity, 181-204. https://doi.org/10.1007/978-1-4419-8059-5_10

Lacey, L. A., Grzywacz, D., Shapiro-Ilan, D. I., Frutos, R., Brownbridge, M. \& Goettel, M. S. (2015). Insect pathogens as biological control agents: Back to the future. Journal of Invertebrate Pathology, 132, 1-41. https://doi.org/10.1016/j.jip.2015.07.009

Lee, S. J., Lee, M. R., Kim, S., Kim, J. C., Park, S. E., Li, D., Shin, T. Y., Nai, Y.-S. \& Kim, J. S. (2018). Genomic Analysis of the Insect-Killing Fungus Beauveria bassiana JEF-007 as a Biopesticide. Scientific Reports, 8(1), 12388. https://doi.org/10.1038/s41598-018-30856-1

Li, J., Ying, S.-H., Shan, L.-T. \& Feng, M.-G. (2010). A new non-hydrophobic cell wall protein (CWP10) of Metarhizium anisopliae enhances conidial hydrophobicity when expressed in Beauveria bassiana. Applied Microbiology and Biotechnology, 85(4), 975-984. https://doi.org/10.1007/s00253-009-2083-8

Litwin, A., Nowak, M. \& Różalska, S. (2020). Entomopathogenic fungi: Unconventional applications. Reviews in Environmental Science and Bio/Technology, 19(1), 23-42. https://doi.org/10.1007/s11157-020-09525-1

López-Pazos, S. A. \& Cerón, J. (2010). Proteínas Cry de Bacillus thuringiensis y su interacción con coleópteros. NOVA, 8(14), Article 14. https://doi.org/10.22490/24629448.449

Moreno, I. M. A. (2012). Bacillus thuringiensis, el ingrediente activo de bioinsecticidas. 17(63). http://www.comprendamos.org/alephzero/63/aleph63.pdf

Muñoz T., P. A. (2018). Microorganismos como una alternativa al uso de agroquímicos. Idesia (Arica), 36(1), 3-5. https://doi.org/10.4067/S071834292018000100003

Ortiz-Urquiza, A. \& Keyhani, N. O. (2013). Action on the surface: Entomopathogenic fungi versus the insect cuticle. Insects 4: 357-374. https://pubmed.ncbi.nlm.nih.gov/26462424/

Pedrini, N., Crespo, R. \& Juárez, M. P. (2007). Biochemistry of insect epicuticle degradation by entomopathogenic fungi. Comparative Biochemistry and Physiology Part C: Toxicology \& Pharmacology, 146(1), 124-137. https://doi.org/10.1016/j.cbpc.2006.08.003

Pigott, C. R. \& Ellar, D. J. (2007). Role of Receptors in Bacillus thuringiensis Crystal Toxin Activity. Microbiology and Molecular Biology Reviews, 71(2), 255-281. https://doi.org/10.1128/MMBR.00034-06

Pucheta, M., Flores-Macías, A., Rodríguez-Navarro, S. y Torre, M. (2006). Mecanismo de acción de los hongos entomopatógenos. Interciencia: Revista de ciencia y tecnología de América, 31(12), 856-860. https://www.redalyc.org/pdf/339/33901204.pdf

Roberts, D. W. \& Humber, R. A. (1981). Entomogenous fungi. Biology of conidial fungi, $2(201)$, e236. https://www.scirp.org/(S(351jmbntvnsjt1aadkposzje))/reference/ReferencesPapers.aspx?ReferenceID=1535851

Rother, E. T. (2007). Revisão sistemática x Revisão Narrativa. Acta Paulista de Enfermagem, 20(2).

Rosas-García, N. M., Avalos-de-León, O., Villegas-Mendoza, J. M., Mireles-Martínez, M., Barboza-Corona, J. E. \& Castañeda-Ramírez, J. C. (2014). Correlation between $\operatorname{Pr} 1$ and $\operatorname{Pr} 2$ gene content and virulence in Metarhizium anisopliae strains. Journal of Microbiology and Biotechnology, 24(11), 14951502. https://doi.org/10.4014/jmb.1404.04044

Samuels, R., Paula, A., Carolino, A., Gomes, S., Paula, C., Cypriano, M., Silva, L., Ribeiro, A., Bastos, J. \& Peres, C. (2016). Entomopathogenic organisms: Conceptual advances and real-world applications for mosquito biological control. Open Access Insect Physiology, 25. https://doi.org/10.2147/OAIP.S68850

Sanchis, V. y Bourguet, D. (2009). Bacillus thuringiensis: Applications in Agriculture and Insect Resistance Management - A Review. En E. Lichtfouse, M. Navarrete, P. Debaeke, S. Véronique y C. Alberola (Eds.), Sustainable Agriculture, 243-255. https://doi.org/10.1007/978-90-481-2666-8_16

Santi, L., Beys da Silva, W. O., Berger, M., Guimarães, J. A., Schrank, A. \& Vainstein, M. H. (2010). Conidial surface proteins of Metarhizium anisopliae: Source of activities related with toxic effects, host penetration and pathogenesis. Toxicon, 55(4), 874-880. https://doi.org/10.1016/j.toxicon.2009.12.012

Schnepf, E., Crickmore, N., Rie, J. V., Lereclus, D., Baum, J., Feitelson, J., Zeigler, D. R. \& Dean, D. H. (1998). Bacillus thuringiensis and Its Pesticidal Crystal Proteins. Microbiology and Molecular Biology Reviews, 62(3), 775-806. https://doi.org/10.1128/MMBR.62.3.775-806.1998

SENASA (2021). Lista de productos biologicos formulados registrados. https://www.senasa.gob.pe/senasa/insumos-inocuidad-organica-semillas/

Sevim, A., Donzelli, B., Wu, D., Demirbag, Z., Gibson, D. \& Turgeon, G. (2012). Hydrophobin genes of the entomopathogenic fungus, Metarhizium brunneum, are diVerentially expressed and corresponding mutants are decreased in virulence. Current genetics, 58, 79-92. https://doi.org/10.1007/s00294-012$0366-6$

Shang, Y., Chen, P., Chen, Y., Lu, Y. \& Wang, C. (2015). MrSkn7 Controls Sporulation, Cell Wall Integrity, Autolysis, and Virulence in Metarhizium robertsii. Eukaryotic Cell, 14(4), 396-405. https://doi.org/10.1128/EC.00266-14 
Sharma, A., Srivastava, A., Shukla, A. K., Srivastava, K., Srivastava, A. K. \& Saxena, A. K. (2020). Entomopathogenic Fungi: A Potential Source for Biological Control of Insect Pests. En M. K. Solanki, P. L. Kashyap y B. Kumari (Eds.), Phytobiomes: Current Insights and Future Vistas, 225-250. https://doi.org/10.1007/978-981-15-3151-4_9

Skinner, M., Parker, B. L. \& Kim, J. S. (2014). Chapter 10-Role of Entomopathogenic Fungi in Integrated Pest Management. En D. P. Abrol (Ed.), Integrated Pest Management, 169-191. https://doi.org/10.1016/B978-0-12-398529-3.00011-7

Tanada, Y. \& Kaya, H. K. (2012). Insect Pathology. Academic Press. https://www.sciencedirect.com/book/9780123849847/insect-pathology

Téllez-Jurado, A., Cruz Ramírez, M. G., Mercado Flores, Y., Asaff Torres, A. \& Arana-Cuenca, A. (2009). Mecanismos de acción y respuesta en la relación de hongos entomopatógenos e insectos. Revista mexicana de https://www.researchgate.net/publication/237041725_Mecanismos_de_accion_y_respuesta_en_la_relacion_de_hongos_entomopatogenos_e_insectos

Uchida, R., Imasato, R., Yamaguchi, Y., Masuma, R., Shiomi, K., Tomoda, H. \& Ōmura, S. (2005). New Insecticidal Antibiotics, Hydroxyfungerins A and B, Produced by Metarhizium sp. FKI-1079. The Journal of Antibiotics, 58(12), 804-809. https://doi.org/10.1038/ja.2005.107

Vachon, V., Laprade, R. \& Schwartz, J.-L. (2012). Current models of the mode of action of Bacillus thuringiensis insecticidal crystal proteins: A critical review. Journal of Invertebrate Pathology, 111(1), 1-12. https://doi.org/10.1016/j.jip.2012.05.001

Villarreal-Delgado, M. F., Villa-Rodríguez, E. D., Cira-Chávez, L. A., Estrada-Alvarado, M. I., Parra-Cota, F. I., Santos-Villalobos, S. de los, VillarrealDelgado, M. F., Villa-Rodríguez, E. D., Cira-Chávez, L. A., Estrada-Alvarado, M. I., Parra-Cota, F. I. \& Santos-Villalobos, S. de los. (2018). El género Bacillus como agente de control biológico y sus implicaciones en la bioseguridad agrícola. Revista mexicana de fitopatología, 36(1), 95-130. https://doi.org/10.18781/r.mex.fit.1706-5

Wang, B., Kang, Q., Lu, Y., Bai, L. \& Wang, C. (2012). Unveiling the biosynthetic puzzle of destruxins in Metarhizium species. Proceedings of the National Academy of Sciences, 109(4), 1287-1292. https://doi.org/10.1073/pnas.1115983109

Wang, C. \& Leger, R. J. S. (2006). A collagenous protective coat enables Metarhizium anisopliae to evade insect immune responses. Proceedings of the National Academy of Sciences, 103(17), 6647-6652. https://doi.org/10.1073/pnas.0601951103

Wang, C., Typas, M. A. \& Butt, T. M. (2002). Detection and characterisation of pr1 virulent gene deficiencies in the insect pathogenic fungus Metarhizium anisopliae. FEMS Microbiology Letters, 213(2), 251-255. https://doi.org/10.1111/j.1574-6968.2002.tb11314.x

Wang, J., Chen, J., Hu, Y., Ying, S.-H. \& Feng, M.-G. (2020). Roles of six Hsp70 genes in virulence, cell wall integrity, antioxidant activity and multiple stress tolerance of Beauveria bassiana. Fungal Genetics and Biology, 144, 103437. https://doi.org/10.1016/j.fgb.2020.103437

Xie, T., Wang, Y., Yu, D., Zhang, Q., Zhang, T., Wang, Z. \& Huang, B. (2019). MrSVP, a secreted virulence-associated protein, contributes to thermotolerance and virulence of the entomopathogenic fungus Metarhizium robertsii. BMC Microbiology, 19(1), 25. https://doi.org/10.1186/s12866-019$1396-8$

Xu, C., Wang, B.-C., Yu, Z. \& Sun, M. (2014). Structural Insights into Bacillus thuringiensis Cry, Cyt and Parasporin Toxins. Toxins, 6(9), 2732-2770. https://doi.org/10.3390/toxins6092732

Zhang, Y., Zhao, J., Fang, W., Zhang, J., Luo, Z., Zhang, M., Fan, Y. \& Pei, Y. (2009). Mitogen-activated protein kinase hog1 in the entomopathogenic fungus Beauveria bassiana regulates environmental stress responses and virulence to insects. Applied and Environmental Microbiology, 75(11), 3787-3795. https://doi.org/10.1128/AEM.01913-08

Zhou, G., Ying, S.-H., Hu, Y., Fang, X., Feng, M.-G. \& Wang, J. (2018). Roles of Three HSF Domain-Containing Proteins in Mediating Heat-Shock Protein Genes and Sustaining Asexual Cycle, Stress Tolerance, and Virulence in Beauveria bassiana. Frontiers in Microbiology, 9. https://doi.org/10.3389/fmicb.2018.01677

Zhu, Y., Pan, J., Qiu, J. \& Guan, X. (2008). Isolation and characterization of a chitinase gene from entomopathogenic fungus Verticillium lecanii. Brazilian Journal of Microbiology, 39(2), 314-320. https://doi.org/10.1590/S1517-83822008000200022 